\title{
UNA ANTROPOLOGÍA A LA BÚSQUEDA DE LA VERDAD SOBRE EL HOMBRE
}

Aportaciones a la medicina actual

\author{
Esteban Fernández-Hinojosa \\ Hospital Universitario Virgen del Rocío \\ Sevilla
}

\begin{abstract}
Resumen: El presente ensayo breve es un diálogo con algunos de los argumentos esgrimidos en el libro Orígenes del hombre. La singularidad del ser humano, de Francisco Rodríguez Valls, especialmente los referidos a la emoción y la racionalidad humanas. De la comprensión de la emoción y la conciencia humanas pueden extraerse aportaciones a la medicina en su afán de salvar al hombre de lo morboso, verdadero significado de la palabra salud.

Palabras claves: emoción, conciencia, salud, medicina, antropología, ciencia.

An anthropology in search of the truth about man. Contributions to current medicine. Abstract: The present brief essay is a dialogue with some of the arguments used in the book Origins of Man. The singularity of the human being, of the author Francisco Rodríguez Valls. One has focused on the arguments that analyze the human emotion and rationality. The understanding of emotion and human consciousness can offer contributions to medicine in its mission to save man from the morbid, true meaning of the word health.

Keywords: emotion, consciousness, health, medicine, anthropology, science.

Recibido: 2 de septiembre de 2019. Aprobado: 15 de noviembre de 2019.
\end{abstract}

En los años 90 del siglo XX el célebre científico Francis Crick y su colaborador Christof Koch anunciaron algo que, más tarde, se convertiría en una iniciativa sin precedentes: la posibilidad de estudiar la conciencia bajo la horma del método científico. Hasta entonces la filosofía había ostentado el dominio en la investigación del complejo mente-cuerpo. La perspectiva científica sometía a incipiente experimentación la respuesta neuronal frente a las diversas experiencias conscientes. De esta guisa las interminables discusiones académicas, que durante décadas tutelaron filósofos como Daniel Dennett o John Searle, perdieron parte del predicamento ejercido sobre aquella — hasta entonces - atónita comunidad científica. 
Lejos de comprender en su integridad los diversos aspectos de la mente humana, los planteamientos experimentales han comenzado a dar respuesta sobre los llamados «correlatos conscientes» de las percepciones, una cuestión no menor entre aquellas que persiguen dilucidar parte de nuestra recóndita naturaleza. Nuevas generaciones de científicos y filósofos buscan ahora contribuir a la que se considera la indagación más importante y trascendente relativa a nuestra identidad, la del ámbito de la conciencia; pero para ello se requiere superar la diversidad de escolásticas y algunos dislates conceptuales. Aunque el presente texto no es lugar para tal debate, resulta inevitable avanzar que la ciencia, en su empeño por conocer las diversas caras de la realidad, no tiene otra alternativa que el diálogo abierto con la filosofía respecto de ese caballo de batalla que representa el complejo fenómeno de la naturaleza de la consciencia, un enigma de tal profundidad e infinidad de matices que apenas se deja captar; casi se diría que un misterio que no se explica ni con la técnica ni con la ciencia, y que siendo real apenas se puede categorizar.

El análisis que sigue no consiste en una revisión crítica de los postulados del libro Orígenes del hombre. La singularidad del ser humano. Esa es una tarea para la que, como clínico, no soy competente y siento que ni siquiera debo intentar en razón de la categoría intelectual, académica y personal demostrada por el autor — de quien, por cierto, tanto he aprendido-. Y que, justamente, es uno de los pensadores del panorama actual más abiertos al diálogo con las diferentes disciplinas antropológicas. Sin embargo, el texto objeto del presente estudio - una antropología que ensaya argumentos para conceder especial dignidad al hombre como ser finito en un universo que no satisface sus deseos infinitos- permite formular ideas que pueden ser fertilizantes en terrenos poco abonados de la medicina, un arte de escaso glamour que con el apoyo de la ciencia busca salvar de lo morboso (que es el sentido al que aspira el término salud) al hombre enfermo (aquel que no se sostiene erguido) mediante su capacidad de curar a veces, y de acompañar, consolar y escuchar siempre. Un diálogo que se ha centrado en los 
Una antropología a la búsqueda de la verdad sobre el hombre

capítulos 4 y 5, que versan sobre el origen de la emoción y del intelecto humano respectivamente.

El estudio de la afectividad es abordado por el autor reconociendo su milenaria tradición, lo que despeja dudas respecto de su presunta novedad en nuestro tiempo. Y refiere de ella que, junto a la racionalidad, constituye parte fundamental de lo que denomina «estructura de la subjetividad humana». Plantea, asímismo, la dificultad que entraña la comprensión de la naturaleza tanto de la afectividad como de la racionalidad. Tal vez ambas dimensiones sean naturalezas diversas. Y quizá a la idea de racionalidad le asigne nuestro autor diversidad de significados, entre ellos, el que hace referencia a una de las más altas instancias de la estructura de nuestra subjetividad como es la conciencia.

El ser humano es una unidad estructuralmente diversa que necesita integrarse existencialmente (pág. 109).

Para nuestro autor el fenómeno afectivo conforma el puente integrador entre las fases mental y biológica del ser humano. En relación a los mecanismos de expresión de la emoción, cada estímulo procedente del medio y que incide en el hombre, posee sus vías nerviosas para descargar la excitación sobrante en expresiones corporales, a modo de mecanismo de compensación que evita el colapso del organismo. De esta hipótesis surge la cuestión lógica que el autor formula acerca de la frustración y el desorden mental en los individuos de sociedades complejas, como si fueran el resultado del deficiente arbitraje de esos mecanismos compensadores a la hora de ofrecer salidas a tensiones acumuladas. Rodríguez Valls eleva la conciencia a la categoría de corifeo en el entramado emocional, un elemento que coopera en la gestión y control de las emociones en la fase corporal.

Siendo claro que la emoción no es una propiedad de exclusividad humana sino compartida por otros mamíferos, a nuestro objeto resulta poco relevante el contencioso que el capítulo plantea entre los defensores de la naturaleza cultural de la emoción (que no siendo inexistente resulta secundaria) y los que defienden su constitución estructural en animales 
superiores (que, siendo ahora una evidencia, es también sensible a la influencia de la cultura). En cambio, es muy relevante el paralelismo ofrecido entre el instinto, director de origen genético de la conducta animal, y la emoción.

Los animales ofrecen respuestas reflejas a las demandas del entorno, y las ejecutan mediante los instintos. Diferentes de la emoción humana, que son respuestas a los contenidos de la mente — consciente o inconscientemente- - Y aunque desencadenadas por situaciones del mundo exterior, las emociones están permeadas por interpretaciones mentales. A su paso por el cerebro límbico, cada flujo de pensamiento abre compuertas a las moléculas que se encarnarán como emociones para hacer única la experiencia que cada hombre o mujer percibe del mundo. Estas respuestas se desencadenan, en ocasiones, con tal espontaneidad que antes de ser verbalizadas se manifiestan como reacciones corporales. Son los pensamientos pre-verbales, suposiciones sin formular que en su mayor parte arraigaron en la niñez.

En la evolución animal, las primeras células nerviosas se especializaron para regular las funciones automáticas, formando el cerebro instintivo, que los humanos compartimos con los reptiles. Más tarde emergió el cerebro mamífero - que por su disposición espacial en el conjunto del encéfalo fue llamado cerebro límbico por los anatómicos franceses-, y que desarrolló la singular cualidad de generar emociones para la comunicación. Y el más reciente ha sido el cerebro racional, presente, hasta donde sabemos, sólo en el ser humano. Por esta configuración cerebral se dice que somos seres tricerebrados.

Ninguna de las grandes revoluciones culturales en la historia universal se ha producido mediante un armónico y compensado cerebro trino de nuestra especie, ningún cambio de época se ha consolidado merced al equilibrio de esta singular estructura de la subjetividad en la mayor parte de los seres humanos.

¿Cómo salen los humanos del atolladero? El éxito se consigue ensayando la integración de las estructuras humanas en una unidad con sentido en la que se otorga a cada parte lo que en justicia le corresponde (pág. 119). 
En la mentalidad moderna, forjada entre cálculos de defensas y ataques, de pérdidas y ganancias..., ha imperado la racionalidad sobre la afectividad, comisionada esta última desde sus albores para la creación de vínculos solidarios y fraternales. La eminencia otorgada a la racionalidad no sólo ha podido enajenar a muchos individuos de nuestra especie, sino que ha distorsionado y caricaturizado la misma dimensión afectiva; creemos que, a fuer de competitiva, autoritaria e hipernormativa no ha contribuido a expandir las fronteras de la conciencia para crear seres más equilibrados y complejos. Todo indica que el paradigma moderno, sujeto a la racionalidad, no ha favorecido el desarrollo armónico de tales dimensiones humanas. Unos párrafos más abajo reconoce que:

La racionalidad no debe suprimir las pasiones, su misión es poner orden [...] Armonizar las exigencias pasionales de acuerdo con los ideales que el ser humano se da a sí mismo (pág. 120).

A este respecto nos interesa recordar que los principios que sentaron las bases de la ciencia moderna disolvieron la ancestral unión entre el cuerpo y las emociones, unas fuerzas que hoy están de regreso para dar soporte a las bases biológicas desarrolladas en neurociencia. Durante más de dos siglos la idea que relacionaba las emociones y la salud corporal fue considerada tabú científico. Paradójicamente mientras se luchaba contra un tipo de dogma se creó inadvertidamente otro, que ahora parece sucumbir. En la década de 1950 el fisiólogo austríaco-canadiense Hans Selye, pionero en el uso del concepto estrés tal y como hoy se concibe, llamó la atención de la comunidad científica por la deletérea influencia que este fenómeno ejerce sobre la salud. Ningún científico ha iluminado los ocultos hilos que tejen la unidad mente-cuerpo como Esther Sternberg. En los años ochenta del pasado siglo, sus trabajos pioneros sobre la intrincada relación entre los sistemas nervioso e inmunológico, y sobre las moléculas inmunológicas que desencadenan actividad cerebral afectando las emociones, dieron un paso de gigante en la comprensión de la naturaleza integrada del ser humano. 
Sternberg examinó las interacciones entre emociones y salud física a través de la experiencia del estrés. La identificación de diversos mediadores químicos ha esclareciendo la comprensión de las bases biológicas de las emociones. No es que la psique, por sí misma, sea fuente de males: hoy se acepta que las emociones no son causa directa de salud o enfermedad, pero sí podrían serlo los mecanismos moleculares subyacentes. Se han identificado vías moleculares vinculadas a determinadas respuestas emocionales que, a su vez, se relacionan estrechamente con enfermedades graves. Las preguntas deben ser reformuladas y centradas sobre aquellos componentes de la respuesta inmune que, además de encender emociones, modifican la homeostasis o equilibrio biológico, tanto en el sentido protector de la salud como en el inductor de enfermedad. Además de detectar hábitos de pensamientos nocivos, cabe también reconocer ahora los mecanismos moleculares que, disparados por esos hábitos de la mente, infunden daño celular.

Otra investigadora americana, Candance Pert, identificó receptores opiáceos en las células del sistema inmune, y más tarde decenas de moléculas mediadoras que ejercen como mensajeros entre los sistemas nervioso, inmunológico y endocrino, permitiendo comprender la red integrada de información que conforman. Se hizo patente que cada parte del organismo "conoce" lo que ocurre en el conjunto cuerpo-mente. No queda clara la jerarquía del sistema nervioso. Los linfocitos o células del sistema inmunitario, como «trozos de cerebro», flotan y circulan a través de la sangre y a lo largo y ancho de todo el organismo. Portan receptores para moléculas asociadas a los estados emocionales más activos. Cada vez que presentamos una interpretación del mundo, el hipotálamo libera las correspondientes moléculas al torrente sanguíneo. Si cada célula inmunitaria posee centenares de miles de receptores en su membrana sensibles a las moléculas mensajeras, se advierte que cada emoción anida en la totalidad del cuerpo. Si la expresión de receptores celulares es modulada por el impacto de las moléculas más abundantes, cabe plantear la posibilidad de 
inducir receptores celulares para las moléculas que derivan de los estados de conciencia más elevados a los que aspirar.

En este sentido, la ciencia puede extraer consecuencias para la medicina, pero no lo está haciendo para la ética, la estética y la cultura. Cada hombre, lo sepa o no, está condicionado - y no determinado— tanto por su genética y como por su entorno cultural; sin embargo, frente a esas dos condiciones hay un elemento misterioso, inexplicado e inexplicable por el método científico, que posee carta verde para franquearlas, un elemento que impulsa la vida y la complejidad del ser humano y del que puede brotar la libertad, la creatividad, la claridad o la compasión haciendo impredecible el curso de la historia y el destino individual. Nos referimos a la conciencia, objeto de estudio en el quinto capítulo de Orígenes del hombre y que se comenta en los párrafos que siguen. Conviene adelantar que la conciencia del hombre contemporáneo se muestra aparentemente fracturada por una suerte de conflictos propios de sociedades complejas que casi la sacan de su quicio. Hay un lastre adicional constituido por un asalto continuo y desordenado de palabras, sonidos e imágenes con el que se convive inevitablemente en la corriente de vida social, y cuyo tráfago el hombre común no puede gestionar ni silenciar para su comprensión, lo que socava la energía psíquica que, en forma de atención dispersa, emerge de su conciencia y altera la capacidad para dirigirla voluntariamente. En la vida saludable es crítico el cultivo de este hábito: hay evidencias que sugieren que en esta alteración hunde sus raíces el anchuroso camino que conduce a déficits afectivos, al sufrimiento y a la enfermedad.

Además de la transmisión de conocimiento positivo y del cultivo de la memoria, nos preguntamos ahora, ¿qué hay de la atención en el aula escolar? Naturalmente que es importante aprender contenidos de las diversas disciplinas o aprender a definir conceptos y a expresarlos con claridad. Escribe Hannah Arendt que «no se puede educar sin al mismo tiempo enseñar; una educación sin aprendizaje se encuentra vacía y, por lo tanto, degenera, con mucha facilidad, en sólo una retórica moral y emocional». No obstante más allá del emotivismo triunfante del actual periodo postmoderno, que 
olvida que por encima de lo que «uno siente», existe el bien y el mal, la excelencia y la infamia, la justica y el desafuero...-, necesitamos reaprender a experimentar el afecto, el drama, la amistad, la traición, la paz, la injusticia o la enfermedad y poner límites a la desenfrenada subjetividad si de formar seres más equilibrados y complejos se trata. Viajar a la profundidad caótica de la intimidad y hacer de ese caos ocasión para generar cierto orden en los contenidos mentales, y regular con algo de armonía la vida instintiva, la afectiva y la intelectual, y de paso, integrar gradualmente la dimensión transcendental a campos tan secularmente cerrados a ello como la pedagogía, la psicología o la propia medicina. Considerarlo materia ajena o irrelevante desvirtúa nuestra realidad antropológica, so pena de enfermar colectivamente.

Nuestro autor aboga por el diálogo político entre tales elementos humanos en aras de poder definir sus fines. La gestión de la voluntad y de la conciencia sobre los impulsos corporales se lleva a cabo a través de las costumbres y los hábitos. Nos recuerda algo tan elemental como decisivo: existe la posibilidad de educar las emociones, no mediante órdenes, sino mediante el diálogo entre instancias. Creemos que en esto tampoco le falta un ápice de razón, dado que en la marginada educación sentimental nos jugamos la posibilidad de adecuar la emoción al propósito vital que nos unifica. Y justifica la integración de las estructuras preexistentes del hombre en su proyecto de libertad. De la reflexión que lleva a cabo de la filosofía de Kierkegaard, refiere que la angustia, como emoción, representa la expresión de la expectación del cuerpo ante los requerimientos del mundo y ante el propio proyecto de libertad.

Justamente la cuestión planteada en el libro sobre si el ser humano puede darse fines a sí mismo sirve al autor para introducir el capítulo de la conciencia. Y lo inicia con una inteligente apuesta por la interdisciplinariedad. Si la investigación de las causas que explican la aparición de la conciencia y su naturaleza no acaban de mostrarse accesibles al método científico, resulta razonable abogar por el método hermenéutico para su 
Una antropología a la búsqueda de la verdad sobre el hombre

comprensión. A partir de los límites del conocimiento aportado por la ciencia el capítulo remite a otra metodología para la construcción de una más amplia y más cabal comprensión de los fenómenos conscientes.

Si lo humano se define por la conciencia, es extraño que aquello que le es fundamental no sea nada más que un accidente (pág. 138).

Apreciamos cierta aporía en las corrientes neurocientíficas naturalistas, que aceptan la conciencia como el resultado de procesos biológicos y de la complejidad de la arquitectura cerebral construida a partir de las instrucciones de moléculas proteicas sintetizadas en los cromosomas, y al mismo tiempo se reconoce en ella la capacidad de trascender esas instrucciones genéticas para dirigir su propio e independiente curso de acción. David Foster Wallace, uno de los escritores más influyentes en lengua inglesa, fue invitado en 2005 a pronunciar un discurso en la ceremonia de graduación de la Universidad de Kenyon, EE. UU, que tituló Esto es agua. En él afirmó que pensar consiste en ejercer un cierto control sobre lo que llama «configuración por defecto» de la mente con la que se nace y que dirige sus monólogos automáticos. Y la conciencia como aquello que permite decidir el foco sobre el que se centra la atención en cada momento y elegir qué sentido se construye de la experiencia. Parecida observación formuló Bertrand Russell al reconocer que había superado frustraciones e insatisfacciones del pasado centrando su atención cada vez más en objetos externos a él mismo: en el estado del mundo, en el conocimiento y en las personas por las que sentía afecto. Por su parte, Wallace padecía una depresión grave - que relacionaba con las dificultades vitales de la infancia- y que sólo lograba reconducir con ayuda de tratamiento farmacológico. Durante los periodos sin tratamiento, su mente se volvía insoportablemente caótica. En el último intento de abandonar definitivamente la medicación, la completa pérdida de sentido, la conciencia de fin — de la que previamente había informado- le llevó al suicidio en 2008.

Algunos seres humanos logran cierta independencia de las demandas procedentes tanto de sus instintos como de su entorno social. Reconocen 
que el gozo y el dolor, como el interés o el aburrimiento son notificaciones que aparecen en el escenario que representa el campo de su conciencia, donde se libran las batallas entre la miseria y la grandeza, y aprenden a ensayar con esos actores y a dirigir voluntariamente la calidad de sus experiencias interiores para proyectar su atención en los propósitos que libremente se imponen a sí mismos. No obstante, el número de los que logran emancipar su conciencia es escaso, lo que probablemente se deba a que el aprendizaje de los mejores hábitos constituye materia de una experiencia dolorosa y lenta.

Retomando la vieja expresión platónica, es cierto que engendrar para el hombre significa crear en la belleza (pág. 139).

El libro apela a la capacidad creativa de la conciencia para «ir más allá de la naturaleza», y a la verdad de los anhelos humanos que están por encima de la eficacia biológica al servicio de la supervivencia. Para nuestro autor, el ser humano no sólo posee la capacidad de actuar por instinto, sobrevivir y reproducirse, como el resto de seres vivos. De acuerdo con ello, creemos que las conciencias más elevadas y complejas de cada tiempo han habilitado competencias para corregir parcialmente las inclemencias de la naturaleza, suavizándola mediante un instrumento que llamamos genéricamente cultura; conciencias de esos niveles aprendieron asímismo a corregir las leyes del mundo arbitrando un entramado legal y de mores, en defensa de la dignidad de todo ser humano, al que llamamos civilización. La naturaleza no tiene en consideración los anhelos humanos y, desde luego, el universo no fue creado para satisfacer los deseos de ninguno de sus diminutos seres. Quizá para quienes logran escasa complejidad, la satisfacción de las demandas genéticas o los reclamos del contexto social constituyan la vía preferente de acceso a la plenitud. Las mentes más sutiles y atentas, entre los bravos hombres prehistóricos, descubrieron que el fuego que brota de la combustión de los árboles sirve para calentar las cuevas y forjar herramientas de metal. ¿Cómo iba una conciencia llena de miedos y de contenidos confusos, hace treinta mil años, a dibujar aquellos caballos en las cuevas de Chauvet, 
en el sur de Francia, y transformar para siempre aquel adverso espacio natural en un abrigo acogedor y sublime? La cultura de cada época ha atesorado suficiente información, organizada en conocimiento, como para que los hombres puedan extraer un discreto plus de armonía en medio de la ruda naturaleza.

Aunque el concepto de caos es irrelevante en ciencias naturales — pues los acontecimientos de la naturaleza son explicables hasta el punto que la misma «teoría del caos» describe las regularidades de dicha naturaleza como resultado del azar-, en ciencias sociales, en cambio, hacen alusión al extraño e inexplicable desorden del hombre y el mundo. La forma de sentirnos depende de cómo interpretamos las vivencias cotidianas, y si se logra armonía interior esta puede añadir no sólo bienestar individual, sino también cierta visión de conjunto de la fragmentaria y oscura estructura del mundo. Y si las ciencias naturales no alcanzan a explicar la naturaleza de la conciencia, nuestro autor defiende que tampoco constituyen el único modelo de comprensión:

Creo que el ser humano como hacedor de saber es sobre todo aquel que siendo espectador de lo real ficciona sobre teorías con la función de hacernos pensar y de que con el ejercicio del pensamiento podamos intentar totalizar el sentido del universo (pág. 157).

Y en este sentido acepta que el hombre, en efecto, ficcione, pero no para engañarse, sino para comprender y comprenderse. Reconoce que las hipótesis, las teorías y los programas de investigación, en cualquier rama del saber y como propuestas para conocer la realidad, no son en sí mismos la realidad. Aquí apreciamos el riesgo que ocultan las «ideologías». Pues contrariamente al modo en que una teoría científica estudia la realidad con el fin de conocerla, la ideología se empeña en ajustar esa realidad a los postulados que acríticamente concibe bajo un primitivo afán de dominio. En el desarrollo de los razonamientos como mecanismo de comprensión, Rodríguez Valls alude sucintamente a algunos aspectos de la fenomenología heideggeriana como aportación a su antropología. 
El ser humano se juega a sí mismo en la tarea de construirse y de construir el mundo que tiene alrededor. La identidad de lo humano no es otra cosa que hacerse valedor de su temporalidad (pág. 161).

Compartimos con el autor la tesis según la cual el hombre que no se hace consciente de su destino como ser libre carecerá de responsabilidad para no desarrollar su existencia al completo «dictado del mundo». Posiblemente así procedemos cuando no se ha ensayado una gestión política — por utilizar los términos del autor- de los contenidos mentales que consolide un hábito del carácter con capacidad de soltar amarras durante los tirones naturales y sociales. Advierte de la enorme dificultad que entrañan las sociedades complejas a la hora de envolverse del silencio como condición necesaria para intuir las voces y verdades interiores.

En la última parte del capítulo se reafirma que donde el ser humano alcanza su máxima expresión es en la toma de conciencia de su propia libertad. Sirviéndonos de un modelo más o menos fenomenológico de la conciencia, basado en la teoría de la información, —utilizado por científicos sociales como M. Csikszentmihaly—, creemos que esa libertad puede concretarse en la decisión de qué pensar y cómo pensar en cada momento, cómo invertir la energía que brota en la propia conciencia en forma de atención, y cómo pautarla ante las demandas del mundo y ante las que proceden de dentro a la hora de experimentar unidad entre las diversas instancias de la propia subjetividad, esto es, entre lo que siente el corazón, lo que quiere la voluntad y lo que piensa la razón. Dicho encaje puede ofrecer implicaciones trascendentales en medicina, y no sólo en el delicado capítulo de las somatizaciones de quienes opacan sus verdades interiores y siguen al pie de la letra los dictados del mundo. En la clínica no es infrecuente ver que aquellos que gobiernan y ordenan su conciencia de libertad también enferman, pero su capacidad para dedicarse a algo que trasciende su yo les ofrece la posibilidad de crear sentido incluso en la natural vorágine de esa adversidad $\mathrm{y}$, al contrario que con la locura del venerado escritor norteamericano, sienten que gobiernan su conciencia, de suerte que deseos y necesidades no satisfechos dejan de ser fuente de sufrimiento adicional. Quizá el infierno 
consista, como ha señalado Csikszentmihaly, en apartar la subjetividad de la corriente de la vida. Lo que viene a ser no estar disponible para el presente, ni siquiera concebir un futuro en el horizonte, y aferrarse al pasado o a los propios intereses egoístas u obstinarse por el confort y la seguridad de la vida al albur de la inercia. No en vano, la palabra diablo en su origen griego (dia ballein) significaba separar, desunir, abdicar de la aportación humilde a la construcción del mundo.

Nadie puede desvincularse por completo de las demandas del entorno o de los caprichos de su naturaleza; ni siquiera parece necesario. Algunos logran tomar distancia de ambas condiciones desde la conciencia de libertad, como expresión máxima de lo humano —en palabras del profesor Rodríguez Valls-, lo que puede ofrecer un poco de luz a la economía de un mundo en cuyo centro se halla «El Hombre ahí, / desnudo bajo la noche y frente al misterio, / con su tragedia a cuestas, / con su verdadera tragedia, / con su única tragedia...», en verso de León Felipe. Si para Rodríguez-Valls el último y supremo estadio de la evolución de la vida lo representa la conciencia de libertad, para otro estudioso coetáneo de la subjetividad humana, Javier Gomá, ese pináculo lo ocupa la dignidad ontológica que todo ser humano porta al nacer; esa aparente divergencia podría estar llamada a una nueva e higiénica meditación en bioética. Concluimos este breve ensayo con la convicción de que, al elegir el difícil proyecto de construcción de un libro como Orígenes del hombre, nuestro autor ofrece su legado de claridad y hermosura a la comprensión de la experiencia del yo. Y dado el anhelo que embarga a los médicos de explicación racional —o razonable— para entendernos y entender el mundo, como a Falstaff, no sólo le agradecemos su ingenio, sino también el que suscita en el lector culto y sensible para emprender caminos de una vida saludable.

\section{Bibliografía}

Arendt, H., Entre el pasado y el futuro, Ocho ejercicios sobre la reflexión política. Barcelona, Herder, 2007.

Csikszentmihalyi, M., The psychology of optimal experience. New York, Harper and Row, 1990. 


\section{Esteban Fernández-Hinojosa}

Gomá Lanzón, J., Dignidad. Galaxia Gutenberg, 2019.

León Felipe, Poemas Completos; edición de José Paulino, Madrid, Visor, 2004.

Russell, B. La conquista de la felicidad. Prólogo de J.L. López Aranguren. Madrid, Colección Austral, 1993.

Wallace, D. F., Esto es agua. Algunas ideas, expuestas en una ocasión especial, sobre cómo vivir con compasión. Flash ensayo, 2012.

Esteban Fernández-Hinojosa estebanfhinojosa@gmail.com 